Article

\title{
Subchronic Toxicity Evaluation of Ethanol Extract of Picria fel-terrae Lour. Leaf in Wistar Rats
}

\author{
Urip Harahap, Yuandani *, Marianne, Hafiza Mitha Agustya, Dira Ummul Azizah \\ and Syari Widia Alfiah \\ Department of Pharmacology, Faculty of Pharmacy, Universitas Sumatera Utara, 5 Jalan Almamater, \\ USU-Kampus, Medan 20155, Indonesia; urip.hrp@gmail.com (U.H.); anne.aceh80@gmail.com (M.); \\ hafiza.mithaag@gmail.com (H.M.A.); dira.azizah@ymail.com (D.U.A.); syari.wiwit@gmail.com (S.W.A.) \\ * Correspondence: yuan_dani@yahoo.com or yuandani@usu.ac.id; Tel.: +62-(061)-822-3558; \\ Fax: +62-(061)-821-9775
}

Received: 30 July 2018; Accepted: 30 August 2018; Published: 4 September 2018

\begin{abstract}
Picria fel-terrae extract has been investigated for its hepatoprotective activity. This current study was conducted to evaluate the subchronic toxic effect of Picria fel-terrae Lour. leaf extract. The subchronic toxicity of ethanol extract of P. fel-terrae leaf was evaluated by OECD (Organization for Economic Cooperation and Development) guidelines. The extract at doses of 125, 250, 500, $1000 \mathrm{mg} / \mathrm{kg}$ body weight (BW) were orally administered to the test animals for 90 days. Signs of toxicity and mortality were observed for 90 days and 118 days. The biochemistry, hematology, macropathology, relative organ weight and histopathology examination was also performed. The macroscopic and microscopic examinations of liver, lung, kidney, spleen and heart displayed normal color and texture after treatment, with ethanol extract $P$. fel-terrae leaf at doses of 125 and $250 \mathrm{mg} / \mathrm{kg} \mathrm{BW}$. The signs of toxicity, mortality, macroscopic and microscopic changes, as well as increasing biochemistry parameters were observed after treatment, with extract at the dose of 500 and $1000 \mathrm{mg} / \mathrm{kg}$ BW. However, the abnormal value of biochemistry parameters was returned to normal when the treatment was stopped. There was no effect on hematological parameters at all doses of extract. The ethanol extract $P$. fel-terrae leaf is untoxic for long-term use at dose 125 and $250 \mathrm{mg} / \mathrm{kg}$ BW. The toxic effect of $P$. fel-terrae at 500 and $1000 \mathrm{mg} / \mathrm{kg}$ BW was reversible.
\end{abstract}

Keywords: subchronic toxicity; Picria fel-terrae extract; macroscopic; microscopic; biochemistry

\section{Introduction}

Picria fel-terrae Lour., in Indonesia known as Pugun Tanoh, is one of the plants of the Linderniaceae family. This plant is widely distributed in Asia, including China, India, Indonesia, Philippines, Malaysia, and Myanmar [1]. Rural people use leaf and latex to heal stomach aches, coughs, scabies, bruises, inflammations, and asthma. Previous research has shown that this plant contains glycosides, flavonoids, saponins and terpenoids [2]. P. fel-terrae studies show it to have pharmacological activities such as antidiabetic, diuretic and anthelmintic agents [3-5].

A previous study also reported that the ethanol extract $P$. fel-terrae leaf was able to inhibit liver damage induced by a combination of rifampin and isoniazid [6]. In fact, the effect is similar to the effect of catechins as potential antioxidants, and has been established as a hepatoprotector [7]. However, the safety assessment of this plant has not been done completely. Therefore, the evaluation of the toxic effect, especially over the long-term should be done to determine a range of safe doses, as well as the toxic effect of high doses or in long-term treatment. The preclinical toxicity is an essential part of the new drug development process, to identify potential human toxicity and estimate the safe dose to be used in humans [8]. 
A plant that will be used as a standard herbal medicine should pass the safety test, which includes acute and subchronic toxicity evaluation [8]. Subchronic toxicity evaluation is a test to determine the toxicity of a compound performed in experimental animals with at least three dosage levels, generally within 90 days [9]. This study aimed to provide information of the untoxic dose P. fel-terrae for clinical use.

\section{Materials and Methods}

\subsection{Plant Material, Extraction and Characterization}

The leaves of Picria fel-terrae Lour. were collected from Pancur Batu, Deli Serdang, Sumatera Utara, Indonesia. The plant identification was confirmed by Herbarium Medanese (MEDA) Universitas Sumatera Utara. Fresh samples were washed, dried and powdered in a grinder and stored in an airtight jar. An amount of $1000 \mathrm{~g}$ of the dried leaf of Pugun Tanoh were extracted with the maceration method using $10 \mathrm{~L}$ ethanol until discoloration. Then the filtrate was evaporated at $40 \pm 2{ }^{\circ} \mathrm{C}$ in a rotary vacuum evaporator and thickened by heating in a water bath at $40 \pm 2{ }^{\circ} \mathrm{C}$. The yield of ethanol extract of Pugun Tanoh leaf was $680 \mathrm{gr}(11.31 \%)$. The leaf extract has been characterized according to guidelines for herbal drugs.

\subsection{Chemical Reagents and Tools}

The chemical reagent used in this study was ethanol (Smartlab, Tangerang Selatan, Indonesia). Formalin $10 \%, \mathrm{Na}_{2} \mathrm{HPO}_{4}, \mathrm{NaH}_{2} \mathrm{PO}_{4}$ and $\mathrm{Na}-\mathrm{CMC}$ (Sodium-Carboxy Methyl Cellulose) were purchased from Sigma Aldrich (St. Louis, MO, USA). The tools used in this research were a rotary evaporator (Heidolph VV-300, Schwabach, Germany), an animal balance (Presica Geniweigher GW-1500, Zurich, Switzerland), a digital balance (Vibra, Tokyo, Japan), rough balance (Ohaus, Parsippany, NJ, USA), and a surgical instrument (Wells Spencer, Marietta, GA, USA).

\subsection{Animals}

All procedures were evaluated by Animal Research Ethics Committees (AREC) Faculty of Mathematics and Natural Science, Biological Department, University of Sumatera Utara with an approval number of 499/KEPH-FMIPA/2017, 15 July 2017. Seventy 6-8 week old, male and female Wistar rats (35 males and 35 females) weighing 120-200 g, were used. Before the experiment began, the animals were acclimatized in the experiment room for 7-14 days with $12 \mathrm{~h}$ of light and $12 \mathrm{~h}$ of darkness. The rats were fed on a standard pellet diet and provided access to water ad libitum.

\subsection{Subchronic Toxicity Study}

The subchronic toxicity evaluation followed OECD (Organization for Economic Cooperation and Development) guidelines [10]. The initial dose of subchronic evaluation was chosen based on the dose that has hepatoprotective activity ( $125 \mathrm{mg} / \mathrm{kb}$ body weight (BW)). The next dose was based on OECD guidelines. Animals were divided into 7 groups of females and males, each consisting of 5 rats:

$\begin{array}{ll}\text { I. } & \text { Na-CMC suspension } 0.5 \% w / v . \\ \text { II. } & \text { P. fel-terrae extract } 125 \mathrm{mg} / \mathrm{kg} \mathrm{BW} . \\ \text { III. } & \text { P. fel-terrae extract } 250 \mathrm{mg} / \mathrm{kg} \mathrm{BW} . \\ \text { IV. } & \text { P. fel-terrae extract } 500 \mathrm{mg} / \mathrm{kg} \mathrm{BW} . \\ \text { V. } & \text { P. fel-terrae extract } 1000 \mathrm{mg} / \mathrm{kg} \mathrm{BW} . \\ \text { VI. } & \text { Satellite control Na-CMC } 0.5 \% w / v \\ \text { VII. } & \text { Satellite Dose } 1000 \mathrm{mg} / \mathrm{kg} \mathrm{BW} .\end{array}$

The treatments were administered orally at a single dose to the test animals for 90 days. The toxic symptoms, mortality and body weight were observed weekly for 90 days. For the satellite groups, the observation continued for 118 days to evaluate the recovery process from the toxic effect. Toxic and 
clinical symptoms in the form of physical behaviors like, diarrhea, salivation and weakness were observed. Strange movements, such as walking backwards and using the abdomen, were performed by placing test animals on a flat field. General observation was then conducted on each group for $2 \mathrm{~h}$. At the end of the study, the animals were weighed and autopsied.

\subsection{Analysis of Hematological and Biochemistry}

Blood for hematological and biochemical clinical parameters were collected by tail, arterial and cardiac arteries. The plasma was used to evaluate hematological parameters. Meanwhile, the serum was used to determine ALT (alanine aminotransferase), AST (aspartate aminotransferase), creatinine, and BUN (blood urea nitrogen) levels.

\subsection{Macroscopic Assessment of the Organs}

The organs (liver, spleen, kidney, lung, and heart) that were taken from the animal were washed to observe the color, surface, and consistency. Thereafter they were dried and weighed to determine the relative organ weights. This was calculated using the following formula:

$$
\text { Weight relative }=\frac{\text { Weight organ }}{\text { Weight animal }}
$$

\subsection{Microscopic Study of the Organs}

The organs were immersed in a $10 \%$ formalin buffer solution and then embedded in paraffin. Slicing was done using a microtome and stained with hematoxylin and eosin and observed using a microscope.

\subsection{Statistical Analysis}

Data were analyzed using the Statistical Package for Social Sciences (SPSS) version 17.0 with Kolmogorov-Smirnov normality test, two-way analysis of variance (ANOVA) and Kruskal Wallis to see differences with significance $(p>0.05)$ between test groups.

\section{Results}

\subsection{Signs of Toxicity}

The observation of the signs of toxicity such as seizure, salivation, changes of fur and skin, changes of eye mucosa, diarrhea, walking with the abdomen and walking backwards was performed for 90 and 118 days. From all the signs of toxicity, only changes in fur, skin and eye mucosa were observed at the doses of 500, $1000 \mathrm{mg} / \mathrm{kg}$ BW and a satellite dose of $1000 \mathrm{mg} / \mathrm{kg}$ BW. The observation of clinical signs were performed based on OECD guidelines. There were 10 mice in one group, consisting of five males and five females. Clinical signs were evaluated qualitatively (presence or absence of the clinical signs). The toxicity of the fur was tangled, dirty, and dull. The healthy skin had no physical/disability, no skin crust and good turgor was formed, i.e., when touched or pulled, the animal's skin was very elastic, and returned to its original (normal) state in a relatively short time. Healthy eyes were those with bright and clean with no abnormalities, such as watery, reddish spots on the cornea, presence of white membranes, such as cataracts, or the presence of dirt and wounds in the corners of the eye. The intensity was not classified, only mentioned presence or absence of clinical signs. The clinical signs appeared after treatment by extract for 90 days. The signs persisted for approximately $1 \mathrm{~h}$. In addition, diarrhea at a dose of $1000 \mathrm{mg} / \mathrm{kg}$ BW on female and male rats was observed.

\subsection{Body Weight Observation}

The monitoring of body weight changes of the animal tested is important to evaluate the effect of the extract on the metabolic status of animals. In this study, none of the animals tested suffered 
weight loss as shown in Table 1. All the treatment and control groups displayed weight gain, so did the females in the control group. The average weekly weight gain of all the treatment and control groups was not statistically significant $(p>0.05)$ and no overweight gain was observed. Hence, the results suggest that the ethanol extract of $P$. fel-terrae leaf did not induce effects on body weight, health status and metabolic growth of the rats.

Table 1. Effect of $P$. fel-terrae leaf extract on body weight (Mean $\pm \mathrm{SD})$.

\begin{tabular}{cccccc}
\hline \multirow{2}{*}{ Group } & Gender & \multicolumn{4}{c}{ Weeks } \\
\cline { 3 - 6 } & & $\mathbf{0}$ & $\mathbf{4}$ & $\mathbf{8}$ & $\mathbf{1 2}$ \\
\hline \multirow{2}{*}{ I } & Female & $155.10 \pm 1.31$ & $160.80 \pm 2.43$ & $166.14 \pm 2.46$ & $175.84 \pm 2.52$ \\
& Male & $151.90 \pm 4.62$ & $167.86 \pm 1.60$ & $171.32 \pm 2.10$ & $178.56 \pm 4.74$ \\
\hline \multirow{2}{*}{ II } & Female & $153.98 \pm 4.88$ & $163.54 \pm 2.06$ & $176.78 \pm 3.89$ & $176.78 \pm 3.89$ \\
& Male & $151.44 \pm 3.96$ & $163.88 \pm 2.67$ & $173.14 \pm 5.07$ & $173.14 \pm 5.07$ \\
\hline \multirow{2}{*}{ III } & Female & $154.34 \pm 4.98$ & $166.72 \pm 2.32$ & $170.08 \pm 2.64$ & $177.52 \pm 3.02$ \\
& Male & $155.86 \pm 4.58$ & $162.14 \pm 3.38$ & $165.02 \pm 3.22$ & $173.70 \pm 2.81$ \\
\hline \multirow{2}{*}{ IV } & Female & $152.04 \pm 4.60$ & $163.20 \pm 3.39$ & $167.88 \pm 3.62$ & $178.56 \pm 1.74$ \\
& Male & $149.54 \pm 4.17$ & $162.66 \pm 1.87$ & $163.70 \pm 2.89$ & $175.92 \pm 4.16$ \\
\hline \multirow{2}{*}{ V } & Female & $150.94 \pm 3.50$ & $164.34 \pm 1.31$ & $169.48 \pm 3.30$ & $176.68 \pm 4.16$ \\
& Male & $152.62 \pm 2.96$ & $164.62 \pm 3.33$ & $168.10 \pm 2.23$ & $177.26 \pm 1.53$ \\
\hline \multirow{2}{*}{ VI } & Female & $157.72 \pm 4.23$ & $162.14 \pm 4.43$ & $172,98 \pm 2.56$ & $181.50 \pm 2.06$ \\
& Male & $152.50 \pm 3.47$ & $159.56 \pm 5.38$ & $174,94 \pm 2.58$ & $183.00 \pm 3.11$ \\
\hline \multirow{2}{*}{ VII } & Female & $155.02 \pm 0.92$ & $157.82 \pm 1.19$ & $158,86 \pm 1.51$ & $168.55 \pm 2.53$ \\
& Male & $154.32 \pm 2.19$ & $158.64 \pm 6.77$ & $161,22 \pm 5.14$ & $174.12 \pm 4.46$ \\
\hline
\end{tabular}

\subsection{Mortality}

There were three rat mortalities observed during the experimental period (90 days) at the dose of 1000 and satellite dose at $1000 \mathrm{mg} / \mathrm{kg}$ BW. The mortality occurred on weeks 7,9 and 10 in the highest dose group. Then, the organ was removed and evaluated. The macroscopic evaluation revealed that the liver was black in color, which indicates the toxicity sign. This mortality may be caused by high dose treatment in long-term use. These results show that ethanol extract of $P$. fel-terrae leaf was not safe to use over the long term, at a dose of $1000 \mathrm{mg} / \mathrm{kg}$ BW.

\subsection{Macroscopic and Microscopic Examination}

Macropathology and histopathology were observed at the end of the experiment over 90 days and 118 days. Liver, spleen, kidney, lung and heart of rats were observed. The $P$. fel-terrae extract at doses of 500 and $1000 \mathrm{mg} / \mathrm{kg}$ BW were different in color and texture. The increased mean of relative organ index on liver and kidney is shown in Table 2. The microscopic evaluation of the liver on treatment groups at the dose of 125 and $250 \mathrm{mg} / \mathrm{kg}$ BW was comparable with control groups. Meanwhile, at the dose of $500 \mathrm{mg} / \mathrm{kg}$ BW there was sinusoidal dilatation, and at dose $1000 \mathrm{of} \mathrm{mg} / \mathrm{kg}$ BW there was necrosis of hepatocyte. This condition was reversible at satellite dose of $1000 \mathrm{mg} / \mathrm{kg}$ BW (Figure 1). The microscopic evaluation of the spleen on treatment groups was comparable with the control groups (Figure 1). The microscopic evaluation of the kidney found that the control group, and the treatment group, at dose of 125 and $250 \mathrm{mg} / \mathrm{kg}$ BW had normal-looking kidney tissue, there was no widening of Bowman space, tubular lumen or necrosis. While in the dose group $500 \mathrm{mg} / \mathrm{kg} \mathrm{BW}$, edema and dilation of the lumen tubulus were observed. At a dose of $1000 \mathrm{mg} / \mathrm{kg} \mathrm{BW}$, edema, dilation tubules, and the widening Bowman occurred (Figure 1). The microscopic evaluation of the lung in the control and treatment group, at the dose of 125 and $250 \mathrm{mg} / \mathrm{kg}$ BW had normal lung tissue, no inflammatory cell inflammation, edema or congestion. However, infiltration of inflammatory cells and congestion were observed at the dose of $500 \mathrm{mg} / \mathrm{kg}$ BW. The extract at a dose of $1000 \mathrm{mg} / \mathrm{kg}$ BW caused infiltration of 
inflammatory cells, edema, and congestion. The microscopic evaluation of the heart showed that there was degeneration of parenchymal that occurred at all levels of a treatment at doses of 125, 250, 500, and $1000 \mathrm{mg} / \mathrm{kg}$ BW. The degeneration hydropic was seen at satellite dose $1000 \mathrm{mg} / \mathrm{kg}$ BW. Necrosis was observed at a dose of $1000 \mathrm{mg} / \mathrm{kg}$ BW. These results suggest that ethanol extract of $P$. fel-terrae leaf had a reversible effect on macroscopic and microscopic examination.

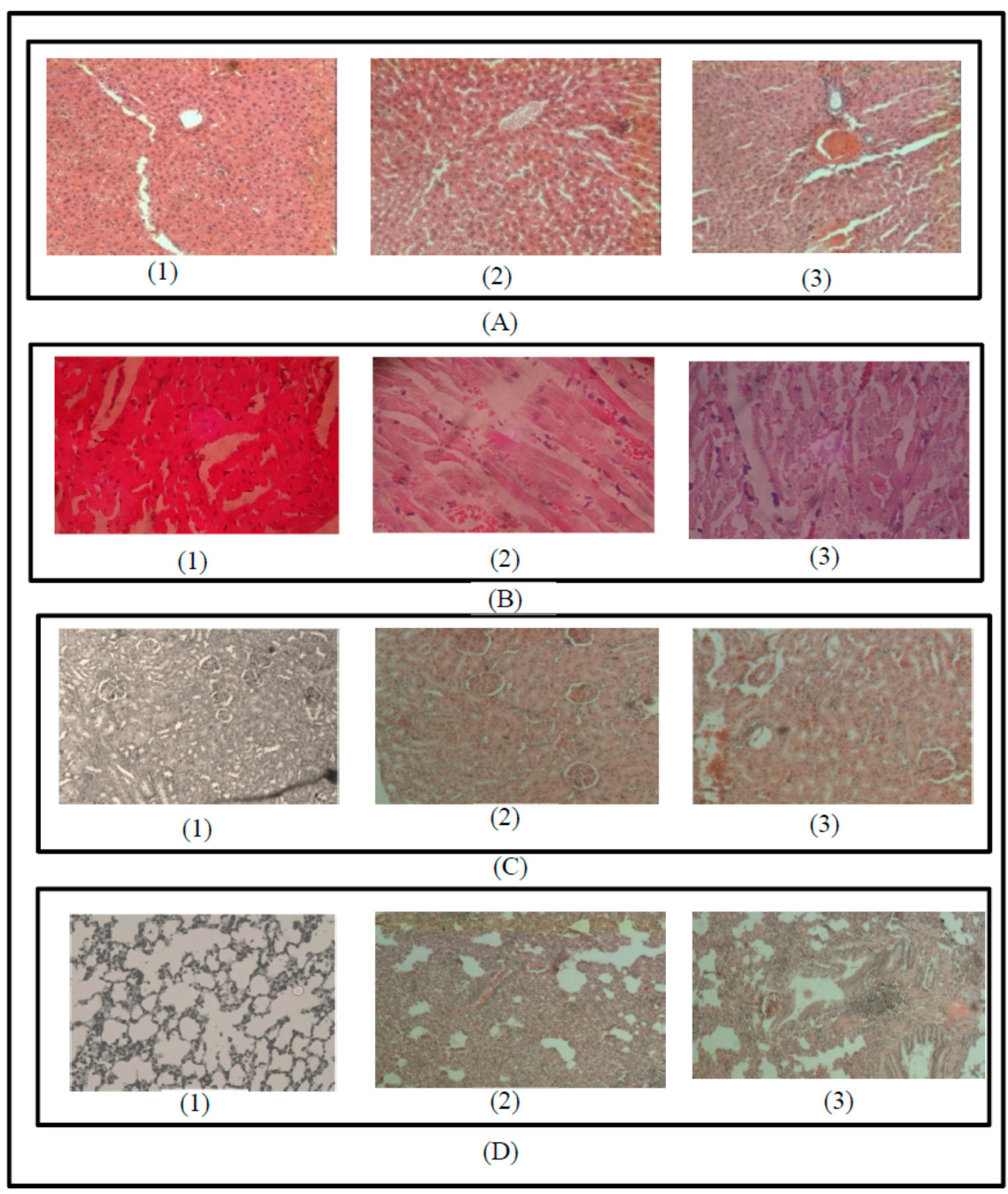

Figure 1. Representative of microscopic changes after treatment with $P$. fel-terrae leaf extract at doses of 500 and $1000 \mathrm{mg} / \mathrm{kg} \mathrm{BW}(10 \times 10)$, scale bars: $10 \times 40$. (A) Liver; (B) heart; (C) kidney; (D) lung; (1) normal group; (2) group of extract at doses of $500 \mathrm{mg} / \mathrm{kg} \mathrm{BW;} \mathrm{(3)} \mathrm{group} \mathrm{of} \mathrm{extract} \mathrm{at} \mathrm{doses} \mathrm{of}$ 1000 mg/kg BW. 
Table 2. Effect of $P$. fel-terrae leaf extract on relative organ index (Mean $\pm \mathrm{SD})$.

\begin{tabular}{ccccccc}
\hline \multirow{2}{*}{ Group } & Gender & \multicolumn{5}{c}{ Mean of Relative Organ Index (100 g) \pm SD } \\
\cline { 3 - 7 } & & Liver & Spleen & Kidney & Lung & Heart \\
\hline \multirow{2}{*}{ I } & Female & $2.86 \pm 0.15$ & $0.24 \pm 0.03$ & $0.37 \pm 0.04$ & $0.37 \pm 0.04$ & $0.37 \pm 0.01$ \\
& Male & $2.63 \pm 0.32$ & $0.22 \pm 0.05$ & $0.37 \pm 0.03$ & $0.37 \pm 0.03$ & $0.35 \pm 0.01$ \\
\hline \multirow{2}{*}{ II } & Female & $4.44 \pm 0.30$ & $0.32 \pm 0.01$ & $0.37 \pm 0.04$ & $0.37 \pm 0.04$ & $0.37 \pm 0.01$ \\
& Male & $3.58 \pm 0.56$ & $0.25 \pm 0.01$ & $0.38 \pm 0.04$ & $0.38 \pm 0.04$ & $0.35 \pm 0.01$ \\
\hline \multirow{2}{*}{ III } & Female & $4.30 \pm 0.53$ & $0.35 \pm 0.02$ & $0.37 \pm 0.03$ & $0.37 \pm 0.03$ & $0.34 \pm 0.02$ \\
& Male & $4.24 \pm 0.42$ & $0.26 \pm 0.07$ & $0.37 \pm 0.02$ & $0.37 \pm 0.02$ & $0.35 \pm 0.01$ \\
\hline \multirow{2}{*}{ IV } & Female & $4.30 \pm 0.53^{*}$ & $0.33 \pm 0.02$ & $0.37 \pm 0.02 *$ & $0.37 \pm 0.02 *$ & $0.34 \pm 0.03$ \\
& Male & $4.24 \pm 0.42^{*}$ & $0.28 \pm 0.03$ & $0.37 \pm 0.03 *$ & $0.37 \pm 0.03 *$ & $0.33 \pm 0.01$ \\
\hline \multirow{2}{*}{ V } & Female & $4.03 \pm 0.05^{*}$ & $0.29 \pm 0.08$ & $0.40 \pm 0.05^{*}$ & $0.40 \pm 0.05^{*}$ & $0.37 \pm 0.00$ \\
& Male & $5.68 \pm 1.66^{*}$ & $0.29 \pm 0.09$ & $0.41 \pm 0.04 *$ & $0.41 \pm 0.04 *$ & $0.36 \pm 0.01$ \\
\hline \multirow{2}{*}{ VI } & Female & $3.97 \pm 0.56$ & $0.30 \pm 0.04$ & $0.39 \pm 0.04$ & $0.39 \pm 0.04$ & $0.31 \pm 0.01$ \\
& Male & $3.92 \pm 0.51$ & $0.28 \pm 0.03$ & $0.39 \pm 0.03$ & $0.34 \pm 0.03$ & $0.33 \pm 0.02$ \\
\hline \multirow{2}{*}{ VII } & Female & $4.01 \pm 0.42$ & $0.34 \pm 0.03$ & $0.42 \pm 0.03$ & $0.42 \pm 0.03$ & $0.34 \pm 0.02$ \\
& Male & $3.86 \pm 0.71$ & $0.26 \pm 0.03$ & $0.42 \pm 0.02$ & $0.42 \pm 0.02$ & $0.36 \pm 0.02$ \\
\hline \multirow{5}{*}{$*$ significantly different within the control group $(p<0.05)}$. &
\end{tabular}

\subsection{Biochemistry Parameters}

The statistical analysis using two-way ANOVA showed that there was no significant difference $(p>0.05)$. The Post-hoc Tukey test showed that there was a significant difference in ALT, AST, creatinine and BUN levels between the control and extract groups at the doses of 500 and $1000 \mathrm{mg} / \mathrm{kg}$ BW (Table 3). The P. fel-terrae extract at the dose of $1000 \mathrm{mg} / \mathrm{kg}$ BW showed an increase in ALT, AST, creatinine and BUN biochemical levels. This was not a significant result $(p>0.05)$ and returned to normal after the treatment stopped which showed in the satellite group at the dose of $1000 \mathrm{mg} / \mathrm{kg}$ BW. These results show the effect of extract ethanol of P. fel-terrae leaf on biochemistry parameters was reversible.

\subsection{Hematological Parameters}

Table 4 shows that there was no significant difference $(p>0.05)$ between the hematological parameter values of each group. Therefore it can be concluded that the ethanol extract of $P$. fel-terrae leaf did not affect the hematology value of the animal test. The values for some controls and some treated animals were in a normal range of the Charles River Laboratories reference [11].

Table 3. Effect of P. fel-terrae leaf extract on biochemistry parameters (Mean $\pm \mathrm{SD}$ ).

\begin{tabular}{cccccc}
\hline Group & Gender & ALT & AST & Creatinin & BUN \\
\hline \multirow{2}{*}{ I } & Female & $58.20 \pm 8.75$ & $211.20 \pm 4.6$ & $0.58 \pm 0.19$ & $48.42 \pm 6.045$ \\
& Male & $50.40 \pm 6.65$ & $207.80 \pm 4.5$ & $0.68 \pm 0.32$ & $50.66 \pm 3.43$ \\
\hline \multirow{2}{*}{ II } & Femae & $58.60 \pm 6.95$ & $215.60 \pm 2.0$ & $0.56 \pm 0.12$ & $48.20 \pm 8.53$ \\
& Male & $50.80 \pm 6.49$ & $211.00 \pm 2.5$ & $0.65 \pm 0.12$ & $49.82 \pm 9.63$ \\
\hline \multirow{2}{*}{ III } & Femae & $63.80 \pm 9.36$ & $220.80 \pm 3.3$ & $0.53 \pm 0.08$ & $48.60 \pm 9.91$ \\
& Male & $50.80 \pm 4.14$ & $216.80 \pm 2.8$ & $0.63 \pm 0.14$ & $64.80 \pm 11.67$ \\
\hline \multirow{2}{*}{ IV } & Femae & $70.60 \pm 7.82^{*}$ & $232.40 \pm 7.7^{*}$ & $0.41 \pm 0.15^{*}$ & $49.80 \pm 13.55^{*}$ \\
& Male & $54.25 \pm 4.78^{*}$ & $216.80 \pm 2.28^{*}$ & $0.65 \pm 0.26^{*}$ & $42.50 \pm 7.59^{*}$ \\
\hline \multirow{2}{*}{ V } & Female & $78.40 \pm 8.20^{*}$ & $246.80 \pm 9.57^{*}$ & $0.60 \pm 0.12^{*}$ & $55.20 \pm 11.88^{*}$ \\
& Male & $71.20 \pm 10.20^{*}$ & $224.75 \pm 2.98^{*}$ & $0.60 \pm 0.20^{*}$ & $45.20 \pm 9.52^{*}$ \\
\hline \multirow{2}{*}{ VI } & Female & $56.00 \pm 5.24$ & $209.40 \pm 4.82$ & $0.42 \pm 0.24$ & $52.40 \pm 10.14$ \\
& Male & $46.60 \pm 7.33$ & $207.20 \pm 3.83$ & $0.63 \pm 0.12$ & $59.60 \pm 7.13$ \\
\hline \multirow{2}{*}{ VII } & Female & $62.60 \pm 5.03$ & $216.50 \pm 3.69$ & $0.61 \pm 0.10$ & $52.75 \pm 0.96$ \\
& Male & $56.25 \pm 5.79$ & $217.25 \pm 3.30$ & $0.66 \pm 0.13$ & $49.50 \pm 3.11$ \\
\hline
\end{tabular}

* Significantly different within the control group $(p<0.05)$. ALT: alanine aminotransferase; AST: aspartate aminotransferase; BUN: blood urea nitrogen. 
Table 4. Effect of $P$. fel-terrae leaf extract on hematological parameters (Mean $\pm \mathrm{SD}$ ).

\begin{tabular}{|c|c|c|c|c|c|c|c|c|c|c|c|c|}
\hline Group & Gender & WBC & RBC & Platelet & Hemoglobin & Hematocrit & МСHC & MCV & $\mathrm{MCH}$ & Eosinofil & Monosit & Basofil \\
\hline \multirow{2}{*}{ I } & Female & $5.98 \pm 0.99$ & $7.93 \pm 0.76$ & $785.60 \pm 117.02$ & .72 & $44.10 \pm 3.33$ & $34.78 \pm 1.58$ & $54.04 \pm 2.03$ & $18.64 \pm 0.88$ & $3.22 \pm 0.61$ & $1.80 \pm 0.84$ & $0.36 \pm 0.13$ \\
\hline & Male & $6.84 \pm 1.23$ & $8.49 \pm 1.23$ & $895.80 \pm 140.94$ & $15.34 \pm 1.25$ & $47.08 \pm 5.41$ & $32.86 \pm 0.99$ & $54.88 \pm 0.79$ & $17.46 \pm 0.68$ & $3.16 \pm 0.63$ & $1.66 \pm 0.63$ & $0.39 \pm 0.09$ \\
\hline \multirow{2}{*}{ II } & Female & $6.75 \pm 1.23$ & $7.94 \pm 0.73$ & $859.20 \pm 189.49$ & $15.48 \pm 1.18$ & $43.86 \pm 3.99$ & $35.54 \pm 2.14$ & $55.82 \pm 1.93$ & $18.78 \pm 0.74$ & $3.24 \pm 0.71$ & $2.16 \pm 0.54$ & $0.37 \pm 0.10$ \\
\hline & Male & $7.73 \pm 1.62$ & $8.95 \pm 0.84$ & $920.20 \pm 175.93$ & $15.16 \pm 0.99$ & $43.54 \pm 4.91$ & $33.58 \pm 2.54$ & $53.96 \pm 3.34$ & $17.84 \pm 0.83$ & $2.94 \pm 0.58$ & $=0.86$ & $0.38 \pm 0.09$ \\
\hline \multirow{2}{*}{ III } & Female & $7.40 \pm 1.05$ & $7.49 \pm 0.43$ & $847.40 \pm 161.39$ & $15.22 \pm 0.91$ & $45.22 \pm 4.01$ & $35.48 \pm 1.64$ & $57.14 \pm 1.36$ & $18.32 \pm 0.70$ & $3.22 \pm 0.86$ & $1.90 \pm 0.89$ & $0.35 \pm 0.08$ \\
\hline & Male & $8.24 \pm 0.95$ & $8.29 \pm 1.04$ & $919.40 \pm 208.39$ & $15.42 \pm 1.26$ & $46.34 \pm 6.15$ & $34.66 \pm 2.52$ & $54.62 \pm 2.92$ & $18.20 \pm 0.82$ & $3.03 \pm 0.22$ & $2.10 \pm 0.64$ & $0.37 \pm 0.11$ \\
\hline \multirow[b]{2}{*}{ IV } & Female & $7.83 \pm 0.83$ & $7.49 \pm 0.81$ & $898.40 \pm 167.42$ & $15.18 \pm 1.12$ & $45.18 \pm 3.47$ & $35.48 \pm 1.64$ & $57.50 \pm 0.78$ & $18.54 \pm 0.50$ & $3.22 \pm 0.86$ & $1.80 \pm 0.67$ & $0.36 \pm 0.09$ \\
\hline & Male & $8.42 \pm 0.64$ & $8.02 \pm 1.17$ & $886.25 \pm 125.31$ & $14.15 \pm 1.15$ & $48.53 \pm 5.74$ & $34.66 \pm 2.52$ & $55.30 \pm 1.92$ & $17.93 \pm 0.83$ & $3.03 \pm 0.22$ & $2.40 \pm 0.76$ & $0.38 \pm 0.12$ \\
\hline \multirow[b]{2}{*}{$v$} & Female & $9.67 \pm 1.16$ & $6.83 \pm 0.65$ & $809.00 \pm 207.26$ & $15.18 \pm 1.07$ & $43.36 \pm 3.09$ & $35.42 \pm 1.60$ & $56.50 \pm 0.93$ & $18.64 \pm 1.10$ & $3.28 \pm 0.63$ & $2.40 \pm 0.82$ & $0.37 \pm 0.10$ \\
\hline & Male & $9.83 \pm 0.79$ & $6.99 \pm 1.34$ & $905.00 \pm 203.02$ & $14.62 \pm 1.41$ & $47.42 \pm 6.37$ & $34.86 \pm 2.82$ & $53.84 \pm 3.07$ & $17.42 \pm 1.12$ & $3.18 \pm 0.58$ & $2.50 \pm 0.46$ & $0.43 \pm 0.11$ \\
\hline \multirow[b]{2}{*}{ VI } & Female & $6.08 \pm 0.77$ & 7.96 & 895.0 & $15.78 \pm 0.69$ & $44.16 \pm 3.31$ & $34.52 \pm 0.68$ & $53.90 \pm 1.77$ & $18.70 \pm 0.57$ & $3.20 \pm 0.60$ & $1.98 \pm 0.72$ & $0.36 \pm 0.07$ \\
\hline & Male & $6.99 \pm 1.43$ & $8.42 \pm 1.26$ & $899.60 \pm 85.93$ & $5.22 \pm 1.18$ & $46.52 \pm 3.78$ & $33.36 \pm 0.83$ & $54.66 \pm 0.48$ & $17.40 \pm 0.53$ & $3.06 \pm 0.62$ & $1.70 \pm 0.47$ & $0.39 \pm 0.03$ \\
\hline \multirow[b]{2}{*}{ VII } & Female & $9.62 \pm 0.6$ & 0.89 & 844 & 0.95 & $.52 \pm 3.78$ & 1.20 & 1.29 & 1 & 62 & 47 & 06 \\
\hline & Male & $9.50 \pm 0.71$ & $7.01 \pm 0.73$ & $1003.75 \pm 109.28$ & $15.35 \pm 0.64$ & $51.65 \pm 2.74$ & $34.08 \pm 2.31$ & $52.99 \pm 0.29$ & $17.23 \pm 0.64$ & $3.18 \pm 0.58$ & $2.38 \pm 0.53$ & $0.43 \pm 0.06$ \\
\hline
\end{tabular}

WBC: White Blood Cells; RBC: Red Blood Cells; MCHC: Mean corpuscular hemoglobin concentration; MCV: Mean corpuscular volume; MCH: Mean Corpuscular Hemoglobin. 


\section{Discussion}

The ethanol extract of $P$. fel-terrae increased the body weight but didn't differ significantly when compared to the normal group. Sensitive indicators for toxicity are clinical symptoms and weight. The animals were observed daily for clinical symptoms and weight was measured periodically. Rapid and meaningful weight loss is usually a sign of poor health. Weight loss can be caused by a lack of food and drink consumption, specific disease or toxic signs [12].

The histopathological and biochemical parameters showed the effect on the liver, lung, kidney, and heart. Mortality after treatment with extract at the dose $1000 \mathrm{mg} / \mathrm{kg}$ BW and increase of ALT, AST, creatinine and blood urea nitrogen levels, after treatment with extract at the dose of 500 and $1000 \mathrm{mg} / \mathrm{kg}$ BW, indicated that there was organ target damage. This result was supported by the histopathology result that showed organs damaged on high dose treatment. The satellite groups showed that all the toxic symptoms, biochemical and pathological disorder response was reversible when the treatment stopped. The previous study reported that the duration and intensity of exposure to toxic substances also can affect the form and toxicity of a particular material [13]. These biochemical responses that may be adaptive, if sustained, lead to change or pathological, and biochemical disorder [14].

Observation of macropathology and relative organ index showed that there was enlargement of liver and kidney after treatment with extract at the dose of $1000 \mathrm{mg} / \mathrm{kg}$. This enlargement may be caused by sodium ion transport interference [15]. Phytochemical screening on P. fel-terrae leaf showed the presence of glycosides, terpenoids, saponins, tannins and flavonoids [2] The toxicity of saponin has been reported which indicated saponin as powerful hemolytics [16]. Flavonoids are polyphenol compounds that act as antioxidants [17]. In this study, treatment was orally administrated for 90 days so that it could increase the concentration of flavonoids in the blood and organ targets. The recent study reported that flavonoid has prooxidant properties which depend on its concentration. Therefore, the long-term exposure of extract which contains flavonoids may induce oxidative damage by reacting with various biomolecules, such as lipids, proteins and DNA [18]. Cell injury in the form of changes in mitochondrial oxidation causing their failure. Failure oxidation can also lead to hydropic degeneration, where there is active transport disruption. The effect on the osmosis process causes an influx of water into the cells which become swollen like vacuoles and the nucleus is enlarged. Hydropic degeneration of cells, previously parenchymal degeneration, is if the cell continues to be exposed to toxic compounds it will continue to develop necrosis [19]. Collectively, these data show that ethanol extract of P. fel-terrae induced significant subchronic toxicity at the dose of 500 and $1000 \mathrm{mg} / \mathrm{kg}$ BW.

\section{Conclusions}

The ethanol extract of $P$. fel-terrae leaf did not induce a toxic effect at the dose of 125 and $250 \mathrm{mg} / \mathrm{kg}$ BW in long term treatment. There was no mortality or macroscopic and microscopic changes observed at the dose of 125 and $250 \mathrm{mg} / \mathrm{kg}$ BW compared to the normal group. In addition, the hematological and biochemistry parameters were still in normal range. The toxic effect started to appear at the middle dose (500 mg/kg BW) and high dose (1000 mg/kg BW) but the effect was reversible, as shown in the satellite group.

Author Contributions: Conceptualization, U.H. and Y.; Methodology, M.; Software, D.U.A.; Validation, U.H., Y. and M.; Formal Analysis, Y.; Investigation, H.M.A., D.U.A., S.W.A..; Resources, M.; Data Curation, U.H.; Writing-Original Draft Preparation, H.M.A.; Writing-Review \& Editing, Y.; Visualization, Y.; Supervision, U.H.; Project Administration, U.H.; Funding Acquisition, M.

Funding: This research was funded by the Ministry of Research, Technology and Higher Education of the Republic of Indonesia through research with grant number of 003/ADD/SP2H/LT/DRPM/VIII/2017.

Acknowledgments: This work was supported by the Ministry of Research, Technology and Higher Education of the Republic of Indonesia through research Penelitian Produk Terapan grant scheme year 2017.

Conflicts of Interest: The authors declare no conflict of interest. 


\section{Abbreviations}

BW body weight

OECD Organisation for Economic Co-Operation and Development

BUN blood urea nitrogen

AST aspartate aminotransferase

ALT alanine aminotransferase

\section{References}

1. Schmelzer, G.H.; Horsten, S.F.A.J. Plant Resources of South-East Asia Leiden; Backhuys Publisher: Leiden, The Netherlands, 2001; pp. 426-428.

2. Juwita, N.A.; Harahap, U.; Dalimunthe, A. Relaxation effect of ethanolic extract of Picria fel-terrae (Pugon tanoh) leaves on contraction of isolated rat's ileum contracted by serotonin. J. Innov. Pharm. Biol. Sci. 2018, 5, 37-41.

3. Kumarasingha, R.; Karpe, A.V.; Preston, S.; Yeo, T.C.; Lim, D.S.L.; Tu, C.L.; Luu, J.; Simpson, K.J.; Shaw, J.M.; Gasser, R.B.; et al. Metabolic profiling and in vitro assessment of anthelmintic fractions of Picria fel-terrae Lour. Int. J. Parasitol. Drugs 2016, 6, 171-178. [CrossRef] [PubMed]

4. Lindarto, D.; Syafril, S.; Zein, U.; Saragih, A. The Effect of dhawalsan-1 (Curanga fel-terrae [Lour.]) extract versus metformin on the metabolic and inflammatory characteristics of patients with newly diagnosed type 2 diabetes mellitus. Asian J. Pharm. Clin. Res. 2016, 9, 225-228.

5. Dalimunthe, A.; Harahap, U.; Rosidah; Nasution, M.P. Evaluation of diuretic activity of Picria fel-terrae Lour leaves extracts. Asian J. Pharm. Clin. Res. 2015, 8, 204-205.

6. Marianne; Chrestella, J.; Ginting, M.A.; Dalimunthe, A.; Nasution, R. Hepatoprotective activity combination of Curanga fel-terrae Lour leaves and Curcuma heyneana valeton and zijprhizome in rat induced by a combination of rifampin and isoniazid. Int. J. Pharm. 2017, 9, 23-28.

7. Ryle, P.R.; Chakraborty, J.; Thomson, A.D. Biochemical mode of action of a hepatoprotective drug: Observations on (+)-catechin. Pharmacol. Biochem. Behav. 1983, 18, 473-478. [CrossRef]

8. Jordan, S.A.; Cunningham, D.G.; Marles, R.J. Assessment of herbal medicinal products: Challenges, and opportunities to increase the knowledge base for safety assessment. Toxicol. Appl. Pharmacol. 2010, 243, 198-216. [CrossRef] [PubMed]

9. OECD. Organization for Economic Cooperation and Development Guidelines for the Testing of Chemicals TG 407; OECD: Paris, France, 2008; pp. 4-13.

10. OECD. Repeated Dose 90-Day Oral Toxicity Study in Rodents TG 408; OECD: Paris, France, 2008.

11. Kayarohanam, S.; Kavimani, S. Acute and sub-acute toxicity study of aqueous methanolic leaf and bark extract of Dolichandrone atrovirens. Int. J. Pharm. 2015, 7, 63-65.

12. CRL (Charles River Laboratories) Technical Bulletin. Baseline Hematology and Clinical Chemistry Values for Charles River Wistar Rats (CRL:(WI)BR) as a Function of Sex and Age; Charles River Laboratories: Wilmington, DE, USA, 1998.

13. Gupta, D.; Bhardwaj, S. Study of Acute, Subacute and Chronic Toxicity Test. Int. J. Adv. Res. Pharm. Biol. Sci. 2012, 1, 103-114.

14. Hastuti, U.S. The Influence of Various Dosages of Citrinin on Hepatocyte Structure Mice (Mus Musculus) Damage to Three Lobulus Hepar Zone. J. Kedokteran Brawijaya 2006, 22, 121-124.

15. Blachley, J.D.; Johnson, J.H.; Knochel, J.P. The harmful effects of ethanol on ion transport and cellular respiration. Am. J. Med Sci. 1985, 289, 22-26. [CrossRef] [PubMed]

16. George, A.J. Legal Status and Toxicity of Saponins. Food Cosmet. Toxicol. 1965, 3, 85-89. [CrossRef]

17. Pietta, P.G. Flavonoids as antioxidants. J. Nat. Prod. 2000, 63, 1035-1042. [CrossRef] [PubMed]

18. Procházkováa, D.; Boušová, I.; Wilhelmováa, N. Antioxidant and prooxidant properties of flavonoids. Fitoterapia 2011, 82, 513-523. [CrossRef] [PubMed]

19. Abdelhalim, M.A.K.; Jarrar, B.M. Gold nanoparticles induced cloudy swelling to hydropic degeneration, cytoplasmic hyaline vacuolation, polymorphism, binucleation, karyopyknosis, karyolysis, karyorrhexis and necrosis in the liver. Lipids Health Dis. 2011, 10, 166. [CrossRef] [PubMed] 